\title{
Moving to another world: Understanding the impact of clinical trial closure on research participants living with HIV in Uganda
}

Sylivia Nalubega, PhD, MSc, BSc, RCN

Karen Cox, PhD, BSc, RGN, Onc Cert, DipHE, DN, FHEA

Henry Mugerwa, MSc (CEB), MBChB

Catrin Evans, PhD, MA, BSc, RGN

Sylivia Nalubega*, PhD, MSc, BSc, RCN, is a lecturer, Soroti University, Soroti, Uganda (syliviaogwang@yahoo.com). Karen Cox, PhD, BSc, RGN, Onc Cert, DipHE, DN, FHEA, is Professor, Vice Chancellor, and President of the University of Kent, Kent, United Kingdom. Henry Mugerwa, MSc (CEB), MBChB, is the Head of Research, Joint Clinical Research Centre, Kamplala, Uganda. Catrin Evans, PhD, MA, BSc, RGN, is Associate Professor, School of Health Sciences, University of Nottingham, Nottingham, United Kingdom.

*Corresponding author: Sylivia Nalubega: syliviaogwang@yahoo.com

\section{Disclosures}

The authors report no real or perceived vested interests related to this article that could be construed as a conflict of interest.

\section{Acknowledgements}

The authors wish to acknowledge the participants who took part in this study for their time and valuable contributions. We wish to acknowledge the participating institutions in this research, for allowing us to undertake the research on their premises. We greatly thank the staff of these institutions for tirelessly contributing toward the recruitment process of the participants. Lastly, we acknowledge the financial support from the Vice-Chancellors Scholarship for Research Excellence (International) and The University of Nottingham, United Kingdom, which facilitated the PhD study for SN. 


\begin{abstract}
Despite an increasing need for clinical trials involving people living with HIV (PLWH), little is known about how PLWH experience trial closure, particularly in low income countries, where the majority of trials take place. We sought to explore the impact of trial closure on PLWH in Uganda. This was an interpretive, grounded theory study using in-depth interviews, conducted between October 2014 and August 2015. Adult participants $(N=23)$ from 3 trials were included. The findings indicated that trial closure was represented as "moving to another world" and was an emotional transition, linked to a loss of quality care in the research environment, the need to find alternative health facilities, fear of experiencing unwanted side effects, a desire to receive trial feedback, and difficulties linking to post-trial care. We concluded that PLWH leaving trials in a resource-limited setting required holistic care to facilitate their transition back to "usual care."
\end{abstract}

Key words: HIV, post-trial care, trial closure, trial participants, Uganda 


\section{Moving to another world: Understanding the impact of clinical trial closure on research participants living with HIV in Uganda}

HIV remains a global threat despite prevention and treatment innovations to curb the epidemic (Global Estimates of Disease 2015 HIV Collaborators, 2016). The research underpinning the majority of new innovations has been conducted in resource-poor settings, and all are potentially associated with uncertain side effects, both in the long and short term (Sofaer et al., 2009). Given the potential impact of new technologies and treatments on quality of life for trial participants, it is important to elicit the experiences and concerns of those who take part in HIV clinical trials and other relevant stakeholders.

Qualitative research has been suggested as an appropriate means for undertaking such investigations (Department of Health [DoH], 2010), and several such studies (Essack et al., 2010; Vallely et al., 2009) have now been conducted. However, most of these studies have involved non-research participants (i.e., general community members) sharing their views on scenarios or hypothetical issues that might arise from hypothetical research participation, or non-community stakeholders (e.g., research professionals, health care providers, or policy makers). Limited studies have been undertaken with participants who have actually taken part in a clinical trial. Those that have, have mainly focused on (a) exploring reasons for trial participation (MacPhail, Delany-Moretlwe, \& Mayaud, 2012; Woodsong et al., 2012) to address concerns about meeting trial recruitment targets, or (b) experiences during the conduct of a trial (Kacanek et al., 2012; Stadler, Delany, \& Mntambo, 2008; Tarimo et al., 2011). Far fewer studies have explored the experience of clinical trial closure, as highlighted in a recent systematic review, which found no studies that examined the experience of HIV trial exit or transition back to usual care (Nalubega \& Evans, 2015). This is a key gap.

Several authors have observed that the area of post-trial care has been neglected in policy, practice, and research (Pratt et al., 2012; Wilson, Elkan, \& Cox, 2007). Post-trial care 
appears to have been paid limited attention compared to other areas, such as informed consent, standards of care during research, and monitoring and management of adverse effects during trial conduct. This gap was also identified in a trial document review by Ciaranello et al. (2009), which aimed to establish the ways in which post-trial services were described in protocols and informed consent forms of antiretroviral clinical trials. Their review found that fewer than $50 \%$ of the documents included details or plans regarding posttrial care, compared to other aspects of the research, which received considerable attention. Similarly, in a systematic survey to establish the reporting of informed consent, standard of care, and post-trial obligations in global registers of randomized control trials in the fields of HIV, malaria, and tuberculosis trials, Cohen, O'Neill, Joffres, Upshur, and Mills (2009), reported that only $1 \%$ of trials described provisions for post-trial benefits. Another study by Shah, Elmer, and Grady (2009), which assessed 18 studies in order to examine whether the National Institutes of Health (NIH) guidance document was being implemented in NIHfunded antiretroviral therapy (ART) trials conducted in developing countries, found that none had a guarantee for long-term sponsor funding after the trials, which limited post-trial care.

Recommendations regarding improvements to post-trial care in non-HIV studies have been made by several authors. For example, a review by Wilson et al. (2007), regarding closure for patients at the end of cancer clinical trials, concluded that researchers should develop specific post-trial care practices (i.e., transition discussions and feedback on the outcomes of trial treatments) to promote participant wellbeing and to enable them to cope with termination of the trial. Similarly, Sofaer et al. (2009), recommended systematic and consistent discussions on post-trial obligations with potential participants beginning at the informed consent process, because this was thought to alleviate participant post-trial anxieties and increase trust in the research.

Raising an additional dimension, Pratt et al. (2012), argued that current ethical 
guidelines on post-trial obligations may be overly generic and, in particular, may be not be suited to the realities of research practice in low-income settings. The authors identified a need to develop post-trial guidelines that were sensitive to local contexts and to the specific needs of different groups of participants. For example, research conducted in low-income settings may necessitate more supportive approaches during trial closure, owing to the impoverished socio-economic status of local communities and to disparities in the quality of care between Trial Health Care Facilities (THF) and Other Health Care Facilities (OHF), which can include government as well as voluntary sector provision. Such guidelines, they argued, should be developed collaboratively by a range of different stakeholders such as the government, researchers, communities, and research sponsors (Pratt et al., 2012). Other authors have noted that research involving chronic conditions such as HIV, carried additional post-trial obligations for researchers, as participants might require ongoing care or treatment following study termination (Sofaer et al., 2009; Unguru, Joffe, Fernandez, \& Yu, 2013). This is also the case for HIV drug trials, where there is a need for continuity of HIV treatment and where questions have arisen following trial closures regarding ongoing access to trial drugs and the incidence and management of unknown side effects of trial drugs, especially when these may not occur for many years (Joint United Nations Programme on HIV/AIDS [UNAIDS], 2012; Sofaer et al., 2009).

Despite calls to improve and clarify post-trial care policies and practices for HIV research in resource-poor settings, there is a dearth of evidence regarding patient experiences during HIV trial closure and post-trial care. Such research is essential to underpin future guideline development in this area.

\section{Research Aim}

We aimed to establish the impact of HIV clinical trial closure on people living with HIV (PLWH) in Uganda. This paper is part of a larger study that aimed to explore how care 
was perceived and enacted in HIV drug trial closure from the perspectives of trial participants and research staff in Uganda (Nalubega, 2017). The motivation to undertake this research stemmed from the first author's experience working as a research nurse in numerous HIV clinical trials, where she witnessed participant distress during trial closure periods when there was no post-trial care plan. After a systematic review was undertaken to explore the views and experiences of participants in HIV research in sub Saharan Africa (Nalubega \& Evans, 2015), it was discovered that there was no empirical evidence in this area and the decision was made to investigate the issue further.

\section{Methods}

An interpretive-constructivist grounded theory approach was adopted (Charmaz, 2014) to establish an in-depth understanding of the post-trial care experience. This method provided explicit but flexible analytic guidelines that directed the process of data collection, inductive analysis, and conceptualization (Higginbottom \& Lauridsen, 2014). Pseudonyms are used to name respondents, the included trials, research institutions, and other health care facilities in order to maintain anonymity. The methods reported in this paper have been reported in detail elsewhere (Nalubega, 2017).

\section{Research Setting}

The study included participants from three trials (Trial 1, Trial 2, Trial 3), from two different research institutions, referred to as A and B. Trial 1 and Trial 3 were conducted in two different sites in institution A: Trial 1 was conducted at an urban site, situated in Kampala, the capital city of Uganda, and Trial 3 was conducted at a peri-urban site, in the eastern part of Uganda. Trial 2 was conducted in institution B, at a peri-urban site located in the western part of Uganda. The three trials were conducted in different social settings, providing a diversity of views and experiences. The trial characteristics and settings are summarized in Table 1 below. 
Table 1

Characteristics of Included Trials

\begin{tabular}{|c|c|c|c|}
\hline Characteristic & Trial 1 & Trial 2 & Trial 3 \\
\hline $\begin{array}{l}\text { Research aim (main } \\
\text { objective) }\end{array}$ & $\begin{array}{l}\text { Test different second } \\
\text { line therapies in } \\
\text { patients failing on a } \\
\text { first line regimen in } \\
\text { Africa }\end{array}$ & $\begin{array}{l}\text { Evaluate the safety of } \\
\text { discontinuing } \\
\text { cotrimoxazole } \\
\text { prophylaxis in adult } \\
\text { PLWH on ART in } \\
\text { Uganda }\end{array}$ & $\begin{array}{l}\text { Investigate } 3 \text { methods } \\
\text { to reduce early } \\
\text { mortality in } \\
\text { individuals starting } \\
\text { ART with severe } \\
\text { immunodeficiency }\end{array}$ \\
\hline $\begin{array}{l}\text { Immune/health } \\
\text { status of trial } \\
\text { participants at } \\
\text { recruitment }\end{array}$ & $\begin{array}{l}\text { All participants were } \\
\text { living with HIV and } \\
\text { immune suppressed } \\
\text { after first line regimen } \\
\text { treatment failure }\end{array}$ & $\begin{array}{l}\text { All participants were } \\
\text { living with HIV and } \\
\text { had achieved sustained } \\
\text { immune restoration }\end{array}$ & $\begin{array}{l}\text { All participants were } \\
\text { living with HIV, with } \\
\text { severe immune } \\
\text { deficiency }\end{array}$ \\
\hline $\begin{array}{l}\text { Prior experience of } \\
\text { specialized HIV } \\
\text { care/treatment } \\
\text { before trial } \\
\text { participation }\end{array}$ & $\begin{array}{l}\text { Had previous } \\
\text { experience }\end{array}$ & $\begin{array}{l}\text { Had previous } \\
\text { experience }\end{array}$ & $\begin{array}{l}\text { No prior experience of } \\
\text { specialized HIV } \\
\text { care/treatment } \\
\text { experiences before } \\
\text { trial participation }\end{array}$ \\
\hline $\begin{array}{l}\text { Contact with pre- } \\
\text { trial HIV treatment } \\
\text { facilities during } \\
\text { research }\end{array}$ & No contact retained & $\begin{array}{l}\text { Retained contact in } \\
\text { routine checkups } \\
\text { every } 3 \text { months at } \\
\text { these facilities }\end{array}$ & $\begin{array}{l}\text { No contact (there were } \\
\text { no pre-trial HIV care } \\
\text { providers) }\end{array}$ \\
\hline $\begin{array}{l}\text { Access to HIV care } \\
\text { and treatment during } \\
\text { research }\end{array}$ & $\begin{array}{l}\text { Received all HIV- } \\
\text { related care and } \\
\text { treatment from the } \\
\text { research site }\end{array}$ & $\begin{array}{l}\text { Received trial regimen } \\
\text { and all treatment } \\
\text { related to OIs from the } \\
\text { research site; routine } \\
\text { HIV care and ART } \\
\text { obtained from pre-trial } \\
\text { care facilities }\end{array}$ & $\begin{array}{l}\text { Received all HIV- } \\
\text { related care and } \\
\text { treatment from the } \\
\text { research site }\end{array}$ \\
\hline $\begin{array}{l}\text { Presence of a public } \\
\text { HIV care facility } \\
\text { attached to the } \\
\text { research institution }\end{array}$ & Present & Not present & Present \\
\hline $\begin{array}{l}\text { Number of trial } \\
\text { participants included } \\
\text { in our study }\end{array}$ & 7 & 8 & 6 \\
\hline
\end{tabular}

All participants were interviewed on the research site premises. Seven interviews took place in research rooms, seven took place in an outside shelter (tent), and seven took place under a tree. For all interviews, there was minimal interruption from the surrounding environment and the overall quality of interviews was good. All interviews took place on working days and within working hours.

\section{Ethical Issues}


Our research was approved by the University of Nottingham United Kingdom and The AIDS Support Organization (TASO) Uganda ethics committees. The study was registered with the Uganda National Council for Science and Technology as SS 3608. All participating institutions provided approval for the research to be undertaken at their institutions and written informed consent was sought and granted by all participants. Pseudonyms were used throughout the research to identify participants.

\section{Recruitment and Data Collection Methods}

We aimed to recruit a maximum of 30 participants in our study. However, being a grounded theory study, the final sample size of 21 participants was linked to an assessment of theoretical saturation. Achieving a balance of gender and geographical setting was also taken into consideration. The researcher was not previously known to trial participants. To preserve confidentiality, participants were first contacted by their former research institutions to ask for permission for the researcher to approach them. This was done using phone calls or a home visit.

The researcher purposefully sampled participants who met the following inclusion criteria: living with HIV infection, in a treatment drug trial that lasted for at least 6 months, and being within 3 to 12 months of trial exit. To screen for eligible trials, the researcher assessed seven major research institutions in Uganda; three sites from two research institutions had trials that met inclusion criteria. After establishing eligible trials, participants were selected using purposive and convenience sampling approaches. This was required as there were limited participants who met the inclusion criteria. For example, some participants in two of the included trials had already completed 12 months so these had to be excluded.

Trial 3, which was still ongoing, had many potential participants who had not yet completed 3 months after trial exit, hence such participants could not be included. We continued to screen and interview participants on an ongoing basis, based on their eligibility, availability, 
and accessibility, and this process was guided by the participants' former research institutions. Being a grounded theory study, theoretical sampling (an approach that aims to collect specific data about an emerging concept) was also used to gather data specific to particular themes as they emerged during the analysis. For example, the theme of financial compensation emerged during our first interviews, and we specifically assessed details about why, how, and when participants wished to be compensated during subsequent interviews. We stopped recruiting participants after realizing theoretical saturation, where further data did not improve the explanations/interpretations made on the categories.

In-depth individual interviews with semi-structured interview guides were used to collect data from post-trial participants. Interviews lasted from 25 to 66 minutes. All interviews were audio-recorded and, where necessary, field notes were taken by the lead researcher, to summarize key points and reflections. Data collection followed an iterative approach, consistent with the grounded theory approach, where initial data analysis informed later data collection (Charmaz, 2014). All interviews were undertaken by the lead researcher, who was a PhD student with substantial training in qualitative research. Translators or the presence of a second party were not required because the interviewer was well conversant with the two languages (Luganda and English) used during the interviews. Data collection took place for 10 months, between October 2014 and August 2015.

\section{Data Analysis}

Interviews were transcribed and, where necessary, translated prior to analysis. All transcription and translation were done by the first author. Data analysis followed the grounded theory approach of open coding, focused coding, axial coding, theoretical coding, and theory construction (Charmaz, 2014). Initial coding, using the line-by-line approach identified all possible meanings from the data, which helped us remain as open as possible to all theoretical possibilities from the data. Some of the initial codes were found to be more 
conceptual and were used as theoretical categories. For example, an initial code of feeling uncertain about post-trial care, gave rise to a more theoretical code of uncertainty about future care and treatment, which was used in the final model. Focused coding, on the other hand, was undertaken to elicit more conceptual codes that represented the data. The process of focused coding eventually led to the identification of concepts, which were transformed into tentative categories. For example, a tentative category of emotional effects of research closure was derived from focused codes (Table 2), and was refined to going through an emotional turmoil, a major theme in the final model.

Table 2

An Example of How Categories Were Developed From Focused Codes

\begin{tabular}{|l|c|}
\hline \multicolumn{1}{|c|}{ Focused codes } & Tentative categories \\
\hline Feeling hopeful about research & \\
Feeling sad about leaving research & \\
Feeling bad about leaving research & \\
Feeling uncertain about a post-trial care institution & Emotional effects of research closure \\
Worrying about transferring to new care facility & \\
Feeling unhappy about research closure & \\
Desiring to continue research participation & \\
\hline Advocating for financial support & \\
Importance of financial empowerment & \\
Encountering transportation difficulties & Economic implications \\
Advocating for financial facilitation & \\
\hline
\end{tabular}

Further analytic processes involved asking relevant questions, which enabled us to expand emerging theoretical interpretations, and diagram data, a process that helped us elicit relationships between different codes, categories, and themes. A core concept was identified by further refining the categories. In our research, the core concept of moving to another world was conceptualized from categories that implied that the process of leaving a clinical trial to join non-trial care appeared to be moving from a favorable to an unfavorable world, two different worlds. NVivo 10 software was used for data organization and management. 


\section{Maintaining Rigor}

To maximize rigor, emerging themes and interpretations were extensively discussed and agreed upon by the whole research team, all of whom had read the original transcripts. In addition, we sought to maximize credibility of the findings by ensuring that themes were well supported by the data and well-illustrated through participant quotes. Careful attention was paid to identify any disconfirming cases and to explore nuances within the themes. For example, participants shared opposing views about the need for financial benefits, where some felt it was necessary and a few felt it was not. Paying attention to divergent views helped to widen our overall understanding of post-trial concerns and contributed to the construction of the theoretical interpretation of the research findings, through careful documentation of the research process and discussions with the aforementioned team. Triangulation of the data was achieved through interviewing participants from different trials. Due to the widely disparate geographical residences of the research participants, it was not possible to undertake member checking.

\section{Reflexivity}

As mentioned above, the first author had worked as an HIV care and research nurse for more than 5 years in Uganda, and thus had considerable experience of the research topic and setting. She strongly felt that improvements needed to be made in research practice and maintained awareness of her pre-existing standpoints and of her status as a health professional. This was achieved through careful memo-ing and ongoing discussions with the research team, in which her views and interpretations were challenged and explored. However, her insider status was an advantage, as she was able to build rapport with participants relatively easily and had a good understanding of the issues they described. 


\section{Results}

The majority of trial participants $(62 \%)$ were female. Trial participants were in the age range of 26 to 59 years, with the majority $(67 \%)$ being 40 years and older. Only one trial participant had attained a university degree; the majority (67\%) were educated below college level, having either stopped school at ordinary or primary levels, or had no education at all. Very few trial participants (14\%) had official employment; the rest depended on small scale jobs, subsistence farming, or other sources of income such as support from families or friends. Ninety percent of the participants resided in rural or peri-urban settings. A summary of demographic characteristics of participants is presented in table 3.

Table 3

\section{Characteristics of Participants}

\begin{tabular}{|l|l|c|}
\hline Gender & Male & 8 \\
\cline { 2 - 3 } & Female & 13 \\
\hline \multirow{5}{*}{ Ages (in years) } & $18-29$ & 3 \\
\cline { 2 - 3 } & $30-39$ & 4 \\
\cline { 2 - 3 } & $40-49$ & 8 \\
\cline { 2 - 3 } & $>50$ & 6 \\
\hline Marital status & Married/cohabiting & 10 \\
\cline { 2 - 3 } & Single & 5 \\
\cline { 2 - 3 } & Divorced/separated & 3 \\
\cline { 2 - 3 } & Widowed & 3 \\
\hline Education & None & 2 \\
\cline { 2 - 3 } & Primary & 6 \\
\cline { 2 - 3 } & Secondary & 6 \\
\cline { 2 - 3 } & College (non degree) & 6 \\
\cline { 2 - 3 } & University & 1 \\
\hline Employment & None & 3 \\
\cline { 2 - 3 } & Subsistence & 6 \\
\cline { 2 - 3 } & Self-employed & 5 \\
\cline { 2 - 3 } & Employed & 7 \\
\hline Residence & Rural & 8 \\
\cline { 2 - 3 } & Peri-urban & 2 \\
\cline { 2 - 3 } & Urban & 11 \\
\hline
\end{tabular}

We sought to establish how PLWH participants understood and experienced care as they transitioned from HIV drug trials to the public health care system or community in Uganda. We report findings related to one particular category, moving to another world, 
which explains the expectations and experiences of post-trial participants during transition from trial to non-trial care.

\section{Moving to Another World}

This category conceptualized the transition of trial participants from Trial Health Care Facilities (THFs) to Other Health Care Facilities (OHFs) in the Ugandan context, representing their feelings and reactions. Participants represented the two contexts as different worlds, owing to the care differences. They felt that moving to an OHF required significant adjustment to adapt to a new world. “... it was now as if I am going to another world..., as if I am transferring to another generation whereby I had to begin afresh learning them slowly by slowly" (Wilberforce, male, 46 years, Trial 3).

The two care contexts were considered to be substantively different in terms of care delivery, where the main aspects of concern were the availability of treatment (especially for opportunistic infections), the nature of staff interactions with clients, provision (or not) of incentives, and clinic waiting times. THFs were usually perceived to offer very high-quality care compared to OHFs and leaving a THF was highly undesirable.

...because the problem up there [at a former $\mathrm{OHF}$, when you come on a date other than your return date, and you haven't been brought on a wheel chair, they mistreat us. You have to first sit and wait, you feel very bad and nobody cares, and they are telling you that you didn't come on appointment, because they informed us that we should go to private facilities (whenever we are sick).... But here [in the THF], whenever you would come sick, the truth is that they would attend to you immediately and give you treatment, which the others $[\mathrm{OHF}]$ do not have. For them you have to suffer a lot to attend to you. (Naluwugge, female, 49 years, Trial 2) 
This perceived care gap shaped the reactions of most of the trial participants when faced with the reality of trial closure. The category, moving to another world, was comprised of two inter-linked themes. The first was related to the emotional impacts and needs of trial participants during the trial closure period, and the second related to the practical experiences and needs of participants during the process of re-linking to OHFs. Table 4 represents a summary of the findings presented in this paper.

Table 4

Summary of Findings Related to Moving to Another World

\begin{tabular}{|c|c|c|}
\hline \multirow{7}{*}{$\begin{array}{l}\text { Moving to } \\
\text { Another } \\
\text { World }\end{array}$} & \multirow{5}{*}{$\begin{array}{l}\text { Going Through an } \\
\text { Emotional Turmoil }\end{array}$} & - Losing quality care and supportive relationships \\
\hline & & - Needing recognition \\
\hline & & - Uncertainty about future care and treatment \\
\hline & & - Fear of side effects from trial interventions \\
\hline & & - Anxiety of not knowing trial outcomes \\
\hline & \multirow{2}{*}{$\begin{array}{l}\text { Dealing with } \\
\text { Practical Challenges }\end{array}$} & - Deciding where to seek care \\
\hline & & - Challenges during re-establishment of care \\
\hline
\end{tabular}

\section{Going Through an Emotional Turmoil}

Trial closure often led to complex emotional reactions among the participants. Some of the emotions included sadness, fear, worry, uncertainty, hopelessness, and despair. These emotions were attributed to factors including the loss of quality care and treatment and of supportive relationships, the need to find alternative care, the possibility of experiencing side effects related to trial interventions, leaving research without knowing trial outcomes, and not feeling recognized for their contributions to research. Many participants expressed negative emotions and impacts when explaining their reactions, care expectations, needs, and experiences of trial closure, as noted in the following sections.

Loss of quality care and supportive relationships. Participants described how trial closure exposed them to a perceived loss of high quality care and treatment in the research facility and loss of other research related benefits. To many, loss of research care meant loss of the best (or only) available and trusted means of access to quality care. Aspects of care that 
most participants were concerned about were the ability to obtain adequate assessment for, and management of, their health conditions; treatments for opportunistic infections; the general approach of the staff; privacy; clinic waiting times; and incentives. Participant narratives expressed how they missed trial-related care when the trial closed.

I missed them [research staff], because we used to come here, few of us so they would care a lot for us. So they would discharge you early, and you would go home early, so you wouldn't delay as they would ensure that they attend to you. So that affected me so much, removing me from here and sending me the other side after my time had ended. I wished if they could extend at least for a year. (Nabakooza, female, 54 years, Trial 2)

In addition to the loss of the quality care and of the valued relationships, participants also missed material benefits when trials closed, leaving them worried about how they would now cope. The majority of trial participants had no income, some were ill, and many depended on material incentives that had been provided in research. Benefits such as transport costs and refreshments were considered important to some participants as the quotes below indicate. "Yes, I missed the food assistance" (Mariako, female, 41 years, Trial 3).

I felt bad because whenever I would come here I would be given some money. They would give transport, so I felt bad and I said I am going to suffer because every time I would collect medications, I would also receive some money. That was the main thing that pained me. (Nabakooza, female, 54 years, Trial 2)

Some participants felt a sense of abandonment when research care was discontinued, and more so when they perceived this to have happened abruptly. Participants felt they required adequate preparation by the researchers before being terminated. Others commented that they still needed, and deserved, the attention and care of researchers even after trial closure. The main reason for this was the fear that specific concerns could arise after trial 
exit, which could only be explained or managed by researchers. They also felt this was a researchers' ethical obligation.

When they were sending off people here, the staff would inform you that, "for you, your time is over, go back where you came from." They never gathered us to inform us that, "we are going to send you back, our research has ended here." For me that's what I thought, that they will again gather us here as they did sometime, and they tell us that, "now, all of you who have been getting your medications from here, you are going back where you came from, we have sent you off. This and this is what we have found." We did not get that. ... But remaining like that is like remaining hanging in the air. So for me, I will continue to insist, so that they can tell me the truth. If I encounter a problem, where can I run to? What advice? (Joel, male, 59 years, Trial 1). Needing recognition. While trial participants acknowledged the voluntary nature of their participation, many felt their commitment and the time spent during research deserved to be recognized and, thus, compensated. Participants pointed out the effort they had put into research participation such as enduring painful procedures and frequent travel, which they felt deserved recognition and compensation. When this did not occur, participants felt disappointed as Aidah expressed:

It (the care at closure) was not enough. Ask me why. Comparing, they would have thanked us, for volunteering, it is not easy. Not everyone can volunteer, maybe they needed to send us with some appreciation, maybe, I even don't know how to tell this to you. I think they would have sent us with an appreciation. Yes, because it is not easy, you come under rain, you come under sunshine, you endure and continue, we spend a full day here, you abandon other responsibilities and you still prefer to come. They ask you this and the other and you endure, they prick you, and you endure, blood gets lost and they call you back. ... It is not easy, at least you need to give a 
person an appreciation. (Aidah, female, 46 years, Trial 2)

Although the majority of trial participants did not have formal employment, they still relied on subsistence work such as cultivation or tending to their animals, hence they felt they deserved to be compensated for the time they would have been doing their work. Some participants also felt they should be compensated for potential risks involved in research participation, even where no harm had occurred. In this case, participants felt the compensation would make up for the risk taken to participate in research and also any risks that might occur after trial participation:

Sincerely - we take medications - but these medications we were taking were for trying (experimentation). You see it? What if you die, and leave your children, you see? It would be good that at the end, there would be some appreciation. So even though it is our lives, but they were also looking for the truth. We also cared and we said let us give it (life) in to establish what works. (Bettinah, female, 33 years, Trial 2) Trial participants with less research experience (such as those in Trial 3) were less likely to express a need for compensation compared to those who had experience in other trials. Hence, previous research experience had an influence on post-trial care expectations. For example, some participants had expected to be given similar incentives as in previous research trials and felt disappointed when this did not happen.

Uncertainty about future care and treatment. Trial closures exposed participants to concerns about future access to HIV care and treatment. The thought of receiving lower standards of care in OHFs instilled fear among trial participants. In addition, some were worried and uncertain when they did not know what type of care to expect after leaving research. For example, Dennison who had no specific HIV care experience before joining research, appeared uncertain about his future care after leaving the research context: I was a bit scared (about the closure) because I knew that maybe where they are 
taking me they will not care for me maybe the same way they have been caring for me here. So, I said maybe they could keep me around, they keep me around within their services so that I could be getting the treatment the same way they have been doing. Because I knew maybe when I go there, maybe they will change that style of the treatment, the way they have been may not remain the same. So I was not happy (about the closure). (Dennison, male, 46 years, Trial 3)

Such uncertainty resulted in participants wanting to remain in THFs and this influenced the choice of a post-trial care facility. Particular concerns were raised regarding access to treatment for opportunistic infections. By the time of trial closure, some participants were still experiencing ill health due to opportunistic infections and were worried about their continued access to treatment. Participant fears about care were partly attributed to the lack of availability of most treatments for opportunistic infections in Ugandan OHFs. Other concerns were related to long waiting hours in public health care facilities and the exposed environment in these facilities, associated with a fear of being seen and being stigmatized. Although most concerns were related to the general environment of OHFs, some participants were specifically worried about access to the trial regimen following trial exit. This was particularly a concern for Trial 1 participants who had been placed on second line HIV regimens, which were less likely to be available in OHFs in Uganda. "So we were wondering that when the study ends, shall we be able to get the real type of drugs we are on?" (Janet, female, 54 years, Trial 1).

Fear of side effects from trial interventions. Stopping trial-related care was also associated with fears related to the possibility of developing side effects from trial interventions. These fears were particularly important to participants in Trial 2, which was double blinded, and individuals could not easily associate side effects to a particular intervention or drug. These fears became more pronounced when participants felt there was 
no opportunity to be in contact with researchers after the closure. Some challenged whether it was fair for the research project not to have mechanisms in place to identify and manage side effects that might occur after trial closure. Participants made strong recommendations to have post-trial follow-up care and monitoring:

You have discontinued the person from the usual type of medication he was taking, and now you prepare him and exit him and inform him that "go, the research has ended." When he reaches there, you would have restarted the medications he had stopped, you have not continued with him to know that after he has restarted it, what problems has he encountered. And even if he encounters a problem and returns here, the program would have closed, he will not find anyone to explain it to. ... For me I would expect that, that would be the correct research that you are aware of what is happening until you finally close. And you come to know that after the closure up to 6 months, what problems have been encountered by those who have participated in the program. (Byekwaso, male, 50 years, Trial 2)

Participants felt it was important for research staff to create follow-up plans, to monitor for possible side effects, and to continue to evaluate participant overall care and wellbeing following trial exit.

... what they would have done is to continue moving, to continue inquiring to know after they have gone back to where they were (before joining research), how have they experienced life where they are; to know that what they were researching has had positive results or not. (Baker, male, 52 years, Trial 2)

Anxiety of not knowing trial outcomes. The need to know trial outcomes was expressed by participants across all trials, although there was variation regarding the timing and types of outcomes preferred across the different trials. Trial 1 participants, for example, 
were particularly concerned about knowing their own personal health outcomes as a result of participating in the trial (rather than general trial outcomes). This could be attributed to the context of Trial 1, where the majority joined the trial while ill and after failing on first line HIV regimens. These participants' priorities, therefore, appeared to be focused on recovery. Joel illustrated this while explaining the need to know trial outcomes.

Outcomes about medications and also on our health, but mostly about our health; you have sent us off, but how have I gone? Have I met your expectations? When you look at where you found me, have I improved? But they have not informed us. We would like to know that, "comparing to how we got you, up to now when we are sending you off, for us we have seen this and this difference." But we didn't get that. So now, for me I went when I wasn't contented. (Joel, male, 59 years, Trial 1)

By contrast, Trial 2 participants seemed to be more concerned about the general trial outcomes. This perspective could be attributed to the context of the trial, where participants were relatively healthy and the trial purpose was to evaluate whether cotrimoxazole could be safely discontinued without causing them further complications regarding HIV management. Many Trial 2 participants appeared anxious to know whether it was safe to discontinue this treatment as it would reduce their pill burdens. In addition, being a randomized controlled trial, participants in the treatment arm stopped taking the medication while others continued. However, because the trial was double blinded, participants did not know which arm they were in. Those who experienced ill health during research or shortly after closure expressed a concern of not being able to relate their current health situation to either taking, or withdrawing from, the treatment under investigation. This was quite a stressful experience and some specifically wanted to know their treatment arm. ".... and also for us to know that this one was on the real septirn, this one was on one without ingredients (placebo)" (Abdu, male, 35 years, Trial 2). 
...so the answer we are looking for is that if a person stopped taking septrin and only takes ARVs (antiretrovirals), can they live? I don't know because we didn't come to know the types, that maybe one was taking this and the other without (ingredients), yes that is the challenge we have, we don't know. (Aidah, female, 46 years, Trial 2) These findings suggested that individual participant or trial characteristics were important in determining the need for, and type of, trial outcomes.

\section{Dealing with Practical Challenges}

In order to ensure that participants living with HIV continued to receive treatment, they needed to be linked to another treatment facility after trial closure. Choosing a care facility was an autonomous decision made by the participants, although their decisions depended strongly on other factors such as their health care needs and their psychosocial and economic contexts. Trial participants required guidance from research staff as they made their choices, and also needed practical support to overcome the barriers associated with being re-established into new care contexts.

Deciding where to seek care. Although participants had the choice of where to seek post-trial care, the process seemed challenging for many. To make their choices, trial participants required adequate information regarding the available care facilities. For example, they needed to know details about service delivery in a given facility, such as the availability of drugs (especially trial regimens). Research staff were expected to be well acquainted with such information and provide it to the participants while preparing them for trial exit. Such information was important because some OHFs may not have all the required HIV services. Although other factors were relevant, many participants indicated that the need for quality care was the major motivation for selecting a given care facility. Quality of care was mainly conceptualized in terms of how easily trial participants could access general health care such as medications and medical investigations, time taken at the clinic, and the 
relationships with care providers. "The thing which made me to select this place (Institution A), they handled me 99 , let me say $100 \%$. The way they handled me is not like other hospitals, that is why I selected to stay here" (Nandi, female, 28 years, Trial 3).

I chose to remain here (institution A) because their care was [very good], first of all I was used to them and I know them physically, their services, I could come, there is no congestion. Because the other places where they were trying to put me, I could see there is a lot of congestion there and a lot of time wastage there. (Dennison, male, 46 years, Trial 3)

The desire for quality care meant that some participants were prepared to accept significant inconvenience (such as transport costs) in order to remain close to facilities that they thought would offer high standards of care. However, in making their decisions, participants also considered other factors, such as indirect costs (e.g., of transport, loss of wages incurred during waiting), direct costs (e.g., having to pay for some medicines), the need to remain in contact with fellow trial participants, the need to receive social/family support, and avoiding HIV stigma.

Challenges during re-establishment into usual care. Some participants expressed concerns regarding getting re-established in post-trial care facilities. For some, this involved going through a new, and usually difficult, (re)registration process. While the registration process was a particular concern for those reporting to facilities different from their pre-trial facilities, our findings suggested that even those returning to their former facilities (e.g., Trial 2 participants) were worried about the process. The challenges were mainly associated with normal work routines and procedures (e.g., clinic hours, not working on weekends or public holidays), but also to facility staff attitudes and behaviors. Janet reported a bad experience during re-establishment into post-trial care. 
Yes they gave me a date, and that date was a Wednesday, and when I came to this place, it was a tug of war. They told me, "You should go back, for us, we don't treat patients on a Wednesday." And I said, "This is what they told me; you see my form." "No, Wednesday is for pregnant women," and is it students, or youth? I still don't know, I am still new in this place, but it was a tug of war. In fact, they didn't refuse, but they kept on saying, "Today you are not supposed to be here, no we are not ...." So first day, then after they considered me and they asked me to give them the papers. I told them that, "I am not here by mistake, those people referred me here, maybe they chose a wrong date, a Wednesday, I don't know whether they know that, ... You see it disturbed me so much as if I was rejected. (Janet, female, 54 years, Trial 1)

Participants who were supported by research staff to re-link to post-trial care (e.g., by escorting them to post-trial facilities) reported fewer challenges. Although very few reported such support, it was an indication that receiving research staff support or not could make a difference in how trial participants experienced the transition process. Participants suggested physical facilitation as a helpful measure to facilitate linkage to post-trial care.

I thought that they would do one thing, when a person is transferring from here, they themselves would take that person. Or the others would come for him/her. For example, when we were coming from facility $\mathrm{D}$, these people came for us themselves. You don't encounter problems. (Joseph, male, 40 years, Trial 1)

Participants in Trials 2 and 3 tended to report fewer negative experiences during the linkage to care process compared to Trial 1 . For Trial 2, this trend could be attributed to continued contact with their pre-trial facilities during research participation, which might have eased the re-establishment process because their client files remained. This finding 
suggested that, while physical facilitation and involvement of stakeholders may be important strategies for facilitating linkage to post trial care, retention of contact with pre-trial care facilities could also be a feasible means of eliminating some of the difficulties to linkage to post-trial care.

\section{Discussion}

Our findings indicated that trial closure was experienced as a significant transition and emotional event. The need to leave the research facilities and return to usual care was described as moving to another world in which the move involved significant emotional turmoil and practical challenges. These were associated with the loss of quality care in the research environment (which was often abruptly terminated), the need to find alternative health facilities in Uganda, fear of experiencing unwanted clinical effects, and the need to receive trial feedback. The discussion below considers these issues further and identifies recommendations for policy and practice.

\section{Providing Emotional Support During Trial Closure}

Our study suggested that trial closure led to significant emotional impacts such as worry, fear, and anxiety among trial participants. The emotional impacts were strongly associated with a perceived loss of the quality of care given in THFs, which was perceived to be far superior to that provided in other Ugandan health care facilities. In addition, participants were worried about leaving research without knowing the trial outcomes, feared developing unwanted side effects, and feared the complex process of establishing care in OHFs. Similar emotional distress associated with the closure of health-related programs has been reported in literature with fear, anger, loss, sadness, and mourning as major reactions (Peck, 2007). Although limited literature exists in this area, some evidence concurs with the findings of our study by suggesting that during closure of research projects, loss of quality care is a major concern (Stephenson et al., 2008). Some authors have recommended the need 
for psychological support from research staff, to allay fear and anxiety, and to assist them to find options for further access to required care (Peck, 2007; Williams, Netten, \& Ware, 2006). The loss of valued relationships, especially of research staff and peers, raised a need to also deal with a loss of relationships during the transition process. Respondents in our study suggested a need for weaning strategies to enable a planned (as opposed to an abrupt) cutoff from research-related care and relationships. This strategy has been suggested by other authors (Davis \& Younggren, 2009; Wilson et al., 2007), as some evidence has indicated that relationships terminated abruptly were more likely to lead to negative emotions (Fragkiadaki \& Strauss, 2012) . However, as the findings of our research suggest, little attention has been paid to understanding the impact of terminating close relationships in research contexts, a problem attributed to a lack of guidelines on this issue (Wilson et al., 2007). Understanding the care needs of trial participants during closure of HIV drug trials in a Ugandan setting by stakeholders engaged in HIV research and regulation such as HIV research organizations, research regulatory authorities, and the government would be a starting point to address this concern.

\section{Facilitating Linkage to, and Continuity of, Post-Trial Care}

Facilitating the linkage-to-care process emerged as a key recommendation from participants. Despite scant literature in this field, there have been indications that some participants may not subsequently engage in care following trial exit (Boghuma, 2012; Clouse et al., 2010). Our findings suggest a need to systematically evaluate the proportions of HIV trial participants who do, and do not, link back to care and to identify trial closure processes that are associated with higher rates of care-linkage. In addition, our study suggests a need to devise better approaches to support linkage to post-trial care for PLWH.

Respondents in our study suggested a more facilitated linkage process, whereby trial facilities proactively ensure that trial participants were linked to, and attended, a new care facility. 
Although there has been a lack of research about the feasibility and acceptability of this approach in a research context, Thompson et al. (2012) have suggested a related model to link PLWH to care following diagnosis.

Findings from our research suggested the need for trial researchers to continue engaging with post-trial participants after they have reported to their new facilities, to ensure the participants have settled in and are receiving appropriate treatments and care, a finding that has been supported by other authors (Boghuma, 2012; Govindasamy, Ford, \& Kranzer, 2012). Nonetheless, due to limited evidence in the post-trial context, further research is recommended to confirm and also to validate the extent of the need for post-trial engagement between researchers and trial participants.

Continuity of HIV care and treatment following research would require continuation of the correct HIV medications and other services. The need to provide trial medications to post-trial participants has been a global concern for various stakeholders and has dominated much of the debate on post-trial care (Haire \& Jordens, 2015). Although these debates have focused on the need to provide trial drugs following research participation, we demonstrated that ex-trial participants have health care concerns that go well beyond the provision of trial drugs. For example, we found that, in addition to ongoing access to trial drugs, continuity of HIV care and treatment also required continued provision of other HIV medications (especially to treat opportunistic infections) and continued psychosocial and financial support. These findings concur with those of other authors (Grady, 2005; Stephenson et al., 2008). Access to the medications that formed the trial intervention was of particular concern for those on a second line regimen, a finding similar to that of Ho (2010). This finding suggests that researchers may need to pay more attention to making preparations for access to trial medications in trials testing second- or third-line HIV medications in low income settings, where these drugs may not yet be widely accessible. 


\section{Monitoring for Possible Side Effects}

The possibility of negative effects occurring sometime after trial closure was a major concern for our participants, which was also documented by Nalubega and Evans (2015) and Sofaer et al. (2009), and authors have cited the need to attend to these needs in trial practice (Ho, 2010; Sofaer et al., 2009). Respondents in our study were particularly concerned about effects that might occur after trial participation, with a possibility of some occurring many years following trial closure, but most attention of researchers and regulatory authorities has focused on side effects occurring during trial conduct. These findings were similar to those identified by Sofaer et al. (2009), where participants expressed fears of problems arising after trial exit. Our participants wanted to be followed for as long a period as possible to capture any likely effects. UNAIDS (2012) also highlighted this concern and recommended particular focus be paid to trials that were likely to have long term effects.

\section{Compensation (Recognition) for Trial Participation}

Our participants voiced a desire for compensation for their contributions and sacrifices. The need to compensate participants in research has been extensively debated, with most literature suggesting similar reasons to those raised in our study (Kwagala, Wassenaar, \& Ecuru, 2010; Uganda National Council for Science and Technology, 2007). Similar to our study, Njue et al. (2015) stated that poor participants required compensation for time spent during research participation. Despite some controversies regarding financial issues in research, authors have agreed that the need to compensate trial participants is genuine (Draper, Wilson, Flanagan, \& Ives, 2009; Kwagala, Wassenaar, \& Ecuru, 2010). Many have also agreed with the idea that determining an appropriate amount for compensation may require discussions between various stakeholders. Others have suggested the need to consider various individual research factors such as the risks involved and the research context (Grady, 2005; UNAIDS, 2012). 


\section{The Need for Trial Feedback}

We found that HIV trial participants want to know the outcomes of the study in a timely manner, in order to (a) ascertain the impact of the research on their own health, (b) allay fears and anxieties associated with possible effects of the trial interventions, and (c) enable them to understand general outcomes of the trials related to the research aim. These findings appeared to be congruent with existing literature and research policy guidelines and debates, which put an emphasis on the need for dissemination of trial outcomes in research practice (UNAIDS, 2012; World Medical Association, 2013). Similar to findings in our study, it has been reported that participants need to know more specific trial outcomes such as treatment allocations (Armstrong et al., 2013; Cox, Moghaddam, Bird, \& Elkan, 2011; Sofaer et al., 2009). In other studies, participants have expressed the need to know their own individualized trial outcomes, such as the effects of an intervention on an individual's health (health outcomes) or the long term effects of their participation in the research study (DixonWoods, Jackson, Windridge, \& Kenyon, 2006; Fernandez et al., 2009). These concerns appear to suggest that trial participants require general and personal trial outcomes, a conclusion similar to what other authors have suggested (Cox et al., 2011; Moutel et al., 2005) Although policy guidelines do not specifically assign the timing for providing trial outcomes, some have suggested the need to provide these to the participants as soon as they are available (UNAIDS, 2012), while others have suggested a period of at least 1 year following the closure of data collection (Fernandez et al., 2012).

\section{Limitations and Implications for Further Research}

Our study included a relatively small number of participants from one country. Although this number was appropriate for a qualitative grounded theory study, further research would be needed to assess the transferability of the findings to other settings. In addition, we undertook a retrospective approach so there may have been recall bias, which 
could have affected the study findings. Finally, we included participants who were relatively engaged, demonstrated by a willingness to be interviewed and by the fact that they had linked to a post-trial care facility (even if they had experienced problems in the process). It was beyond the scope of our study to identify trial participants who had not been able to link to care, but future studies should seek to involve these individuals.

\section{Conclusion}

We have shown that trial closure is a complex phenomenon for PLWH in a resource limited setting, requiring psychological, social, and economic adjustments. Ethical debates/guidelines on HIV trial closure have focused on the need to ensure access to trial drugs after the closure; however, we have underscored the need for a more comprehensive approach to manage the holistic care needs of trial participants during transition from research to non-research care, including the careful facilitation of re-establishment into nonresearch care contexts. 


\section{References}

Armstrong, N., Jackson, C. J., McNicol, S., Dixon-Woods, M., Kenyon, S., \& Tarrant, C. (2013). Unblinding following trial participation: Qualitative study of participants' perspectives. Clinical Trials, 10(1), 97-103. doi:10.1177/1740774512464726

Boghuma, K. T. (2012). Ethical riddles in HIV research. Retrieved from http://www.tedxgoodenoughcollege.com/portfolio/boghuma-kabisen-titanji-ethicalriddles-in-hiv-research/

Charmaz, K. (2014). Constructing grounded theory ( $2^{\text {nd }}$ ed.). Thousand Oaks, CA: Sage.

Ciaranello, A. L., Walensky, R. P., Sax, P. E., Chang, Y., Freedberg, K. A., \& Weissman, J. S. (2009). Access to medications and medical care after participation in HIV clinical trials: A systematic review of trial protocols and informed consent documents. $H I V$ Clinical Trials, 10(1), 13-24. doi:10.1310/hct1001-013

Clouse, K., Montgomery, E. T., Milford, C., Watadzaushe, C., Nkala, B., Fancher, H., .. . van der Straten, A. (2010). Establishing a continuum of care between HIV prevention trials and public healthcare systems: The MIRA Standard of Care program. Clinical Trials, 7(3), 256-264. doi:10.1177/1740774510368299

Cohen, E. R., O'Neill, J. M., Joffres, M., Upshur, R. E., \& Mills, E. (2009). Reporting of informed consent, standard of care and post-trial obligations in global randomized intervention trials: A systematic survey of registered trials. Developing World Bioethethics, 9(2), 74-80. doi:10.1111/j.1471-8847.2008.00233.x

Cox, K., Moghaddam, N., Bird, L., \& Elkan, R. (2011). Feedback of trial results to participants: A survey of clinicians' and patients' attitudes and experiences. European Journal of Oncology Nursing, 15(2), 124-129. doi:10.1016/j.ejon.2010.06.009

Davis, D. D., \& Younggren, J. N. (2009). Ethical Competence in Psychotherapy Termination. Professional Psychology: Research and Practice, 40(6), 572-578. 
doi:http://dx.doi.org/10.1037/a0017699

Department of Health. (2010). How to use qualitative research evidence when making decisions about interventions. Retrieved from http://www.health.vic.gov.au/health promotion/evidence evaluation/cdp_tools.htm

Dixon-Woods, M., Jackson, C., Windridge, K. C., \& Kenyon, S. (2006). Receiving a summary of the results of a trial: qualitative study of participants' views. British Medical Journal, 332(7535), 206-210. doi:10.1136/bmj.38675.677963.3A

Draper, H., Wilson, S., Flanagan, S., \& Ives, J. (2009). Offering payments, reimbursement and incentives to patients and family doctors to encourage participation in research. Family Practice, 26(3), 231-238. doi:10.1093/fampra/cmp011

Essack, Z., Koen, J., Barsdorf, N., Slack, C., Quayle, M., Milford, C., . . Mukuka, R. (2010). Stakeholder perspectives on ethical challenges in HIV vaccine trials in South Africa. Developing World Bioethics, 10(1), 11-21. doi:10.1111/j.1471-8847.2009.00254.x

Fernandez, C. V., Gao, J., Strahlendorf, C., Moghrabi, A., Pentz, R. D., Barfield, R. C., . . Kodish, E. (2009). Providing research results to participants: Attitudes and needs of adolescents and parents of children with cancer. Journal of Clinical Oncology, 27(6), 878-883. doi:10.1200/jco.2008.18.5223

Fernandez, C. V., Ruccione, K., Wells, R. J., Long, J. B., Pelletier, W., Hooke, M. C., . . Joffe, S. (2012). Recommendations for the return of research results to study participants and guardians: A report from the Children's Oncology Group. Journal of Clinical Oncology, 30(36), 4573-4579. doi:10.1200/jco.2012.45.2086

Fragkiadaki, E., \& Strauss, S. M. (2012). Termination of psychotherapy: The journey of 10 psychoanalytic and psychodynamic therapists. Psychology and Psychotherapy: Theory, Research and Practice, 85(3), 335-350. doi:10.1111/j.20448341.2011.02035.x 
Global Estimates of Disease 2015 HIV Collaborators. (2016). Estimates of global, regional, and national incidence, prevalence, and mortality of HIV, 1980-2015: The Global Burden of Disease Study 2015. Lancet HIV, 3(8), e361-e387. doi:10.1016/s23523018(16)30087-x

Govindasamy, D., Ford, N., \& Kranzer, K. (2012). Risk factors, barriers and facilitators for linkage to antiretroviral therapy care: a systematic review. Aids, 26(16), 2059-2067. doi:10.1097/QAD.0b013e3283578b9b

Grady, C. (2005). Payment of clinical research subjects. Journal of Clinical Investigation, 115(7), 1681-1687. doi:10.1172/JCI25694

Haire, B., \& Jordens, C. (2015). Mind the gap: An empirical study of post-trial access in HIV biomedical prevention trials. Developing World Bioethics, 15(2), 85-97. doi:10.1111/dewb.12039

Higginbottom, G., \& Lauridsen, E. I. (2014). The roots and development of constructivist grounded theory. Nursing Research, 21(5), 8-13. doi:10.7748/nr.21.5.8.e1208

Ho, J. (2010). HIV vaccine clinical trials, The standard of care debate. Retrieved from http://www.vaccineethics.org/issue_briefs/HIV_standard_of_care.php

Joint United Nations Programme on HIV/AIDS. (2012). Ethical considerations in biomedical HIV prevention trials. Retrieved from http://www.unaids.org/en/resources/documents/2012/20120701_jc1399_ethical_consi derations

Kacanek, D., Dennis, A., Sahin-Hodoglugil, N. N., Montgomery, E. T., Morar, N., Mtetwa, S., . . van der Straten, A. (2012). A qualitative study of obstacles to diaphragm and condom use in an HIV prevention trial in sub-Saharan Africa. AIDS Education and Prevention, 24(1), 54-67. doi:10.1521/aeap.2012.24.1.54

Kwagala, B., Wassenaar, D., \& Ecuru, J. (2010). Payments and direct benefits in HIV/AIDS 
related research projects in Uganda. Ethics \& Behavior, 20(2), 95-109.

doi:10.1080/10508421003595927

MacPhail, C., Delany-Moretlwe, S., \& Mayaud, P. (2012). 'It's not about money, it's about my health': Determinants of participation and adherence among women in an HIVHSV2 prevention trial in Johannesburg, South Africa. Patient Preference and Adherence, 6, 579-588. doi:10.2147/ppa.s30759

Moutel, G., Duchange, N., Raffi, F., Sharara, L. I., Theodorou, I., Noel, V., . . Leport, C. (2005). Communication of pharmacogenetic research results to HIV-infected treated patients: standpoints of professionals and patients. European Journal of Human Genetics, 13(9), 1055-1062. doi:10.1038/sj.ejhg.5201450

Nalubega, S. (2017). Care in HIV drug trial closure: Perspectives of research participants and staff in Uganda. Retrieved from http://eprints.nottingham.ac.uk/43339/1/SYLIVIA\%20NALUBEGA$\% 20 \mathrm{PhD} \% 20$ THESIS.pdf\%E2\%80\%99

Nalubega, S., \& Evans, C. (2015). Participant views and experiences of participating in HIV research in sub-Saharan Africa: A qualitative systematic review. JBI Database of Systematic Reviews and Implementation Reports, 13(5), 330-420. doi:10.11124/jbisrir-2015-2051

Njue, M., Molyneux, S., Kombe, F., Mwalukore, S., Kamuya, D., \& Marsh, V. (2015). Benefits in cash or in kind? A community consultation on types of benefits in health research on the Kenyan Coast. PLoS ONE, 10(5), e0127842. doi:10.1371/journal.pone.0127842

Peck, S. (2007). Aftermath of the unexpected, unexplained, and abrupt termination of healing touch and extrapolation of related costs. Complementary Health Practice Review, 12(2), 144-160. doi:10.1177/1533210107302934 
Pratt, B., Zion, D., Lwin, K. M., Cheah, P. Y., Nosten, F., \& Loff, B. (2012). Closing the translation gap for justice requirements in international research. Journal of Medical Ethics, 38(9), 552-558. doi:10.1136/medethics-2011-100301

Shah, S., Elmer, S., \& Grady, C. (2009). Planning for posttrial access to antiretroviral treatment for research participants in developing countries. American Journal of Public Health, 99(9), 1556-1562. doi:10.2105/ajph.2008.157982

Sofaer, N., Thiessen, C., Goold, S. D., Ballou, J., Getz, K. A., Koski, G., . . Weissman, J. S. (2009). Subjects' views of obligations to ensure post-trial access to drugs, care and information: Qualitative results from the Experiences of Participants in Clinical Trials (EPIC) study. Journal of Medical Ethics, 35(3), 183-188.

doi:10.1136/jme.2008.024711

Stadler, J. J., Delany, S., \& Mntambo, M. (2008). Women's perceptions and experiences of HIV prevention trials in Soweto, South Africa. Social Science \& Medicine, 66(1), 189-200. doi:10.1016/j.socscimed.2007.08.021

Stephenson, R., Shutes, E., McKenna, S., Allen, S., Brill, I., Kancheya, N., . . Chomba, E. (2008). The impact of project closure on HIV incidence and mortality in a cohort of couples in Lusaka, Zambia. AIDS Care, 20(6), 683-691.

doi:10.1080/09540120701593505

Tarimo, E. A., Thorson, A., Kohi, T. W., Bakari, M., Sandstrom, E., Mhalu, F., \& Kulane, A. (2011). A qualitative evaluation of volunteers' experiences in a phase I/II HIV vaccine trial in Tanzania. BMC Infectious Diseases, 11, 283. doi:10.1186/1471-2334-11-283

Thompson, M. A., Mugavero, M. J., Amico, K. R., Cargill, V. A., Chang, L. W., Gross, R., . . . Nachega, J. B. (2012). Guidelines for improving entry into and retention in care and antiretroviral adherence for persons with HIV: Evidence-based recommendations from an International Association of Physicians in AIDS Care panel. Annals of 
Internal Medicine, 156(11), 817-833. doi:10.7326/0003-4819-156-11-20120605000419

Uganda National Council for Science and Technology. (2007). National guidelines for research involving humans as research participants. Retrieved from https://docplayer.net/50072-National-guidelines-for-research-involving-humans-asresearch-participants.html

Unguru, Y., Joffe, S., Fernandez, C. V., \& Yu, A. L. (2013). Ethical issues for control-arm patients after revelation of benefits of experimental therapy: A framework modeled in neuroblastoma. Journal of Clinical Oncology, 31(5), 641-646.

doi:10.1200/jco.2012.47.1227

Vallely, A., Shagi, C., Lees, S., Shapiro, K., Masanja, J., Nikolau, L., . . Hayes, R. J. (2009). Microbicides Development Programme: Engaging the community in the standard of care debate in a vaginal microbicide trial in Mwanza, Tanzania. BMC Medical Ethics, 10, 17. doi:10.1186/1472-6939-10-17

Williams, J., Netten, A., \& Ware, P. (2006). Managing the care home closure process: Care managers' experiences and views. British Journal of Social Work, 37(5), 909-924. doi:10.1093/bjsw/bcl034

Wilson, E., Elkan, R., \& Cox, K. (2007). Closure for patients at the end of a cancer clinical trial: Literature review. Journal of Advanced Nursing, 59(5), 445-453. doi:10.1111/j.1365-2648.2007.04377.x

Woodsong, C., Alleman, P., Musara, P., Chandipwisa, A., Chirenje, M., Martinson, F., \& Hoffman, I. (2012). Preventive misconception as a motivation for participation and adherence in microbicide trials: Evidence from female participants and male partners in Malawi and Zimbabwe. AIDS and Behavior, 16(3), 785-790. doi:10.1007/s10461011-0027-7 
World Medical Association. (2013). World Medical Association Declaration of Helsinki:

Ethical principles for medical research involving human subjects. Journal of the American Medical Association, 310(20), 2191-2194. doi:10.1001/jama.2013.281053 


\section{Key Considerations}

- Exiting from HIV clinical trials is a stressful event for PLWH in low income settings where there is disparity between care provided in research and non-research care facilities and, therefore, emotional support is required during the trial closure period.

- Linking back to HIV care can be challenging for research participants who did not retain contact with their former care facilities; practical support should be provided during transition to non-research care.

- Trial participants living with HIV require trial feedback and it is important for researchers to provide the feedback in a timely manner.

- Monitoring for possible side effects from trial interventions following trial closure is a serious concern in trials involving PLWH and should be implemented. 